\title{
One-Step Twin-Screw Extrusion Process to Fibrillate Deep Eutectic Solvent-Treated Wood to Be Used in Wood Fiber-Polypropylene Composites
}

\author{
Hesam Taheri, Maiju Hietala, Terhi Suopajärvi, Henrikki Liimatainen, and Kristiina Oksman*
}

Cite This: ACS Sustainable Chem. Eng. 2021, 9, 883-893

Read Online

S1 Supporting Information

ABSTRACT: Bio-based wood materials are preferable for composites because of their sustainability, but adequately dispersing wood fibers in polymers can be difficult and costly. Our approach was to pretreat the wood with a green solvent system, allowing the composite to be extruded in a single step, simplifying the process, and reducing the overall cost. This study investigates the fibrillation of untreated wood sawdust (W) and deep eutectic solvent-treated wood sawdust (DESW) using a one-step twin-screw extrusion (TSE) process. The results of the analysis of wood fractions and optical microscopy confirmed that the one-step extrusion process resulted in fibrillation of both treated and untreated wood material. The width of the

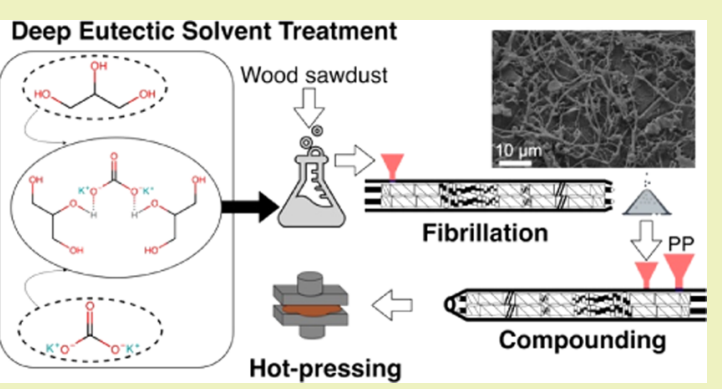
original wood particles was reduced by more than $99 \%$ after a one-step TSE for both untreated and DES-treated wood. The size reduction of the DESW was slightly greater than that of the untreated wood, and fibrillation was further confirmed by rheological analysis. The fibrillated wood was then compounded with polypropylene (PP) to produce a wood fiber-polypropylene composite with $50 \mathrm{wt} \%$ wood content. The elastic modulus of both untreated and treated extruded composites was higher than that of neat PP. The tensile strength and strain at break for the DESW-PP composite slightly increased in comparison to the untreated W-PP composite. Furthermore, DES treatment of wood resulted in a darker color and increased hydrophobicity of the material.

KEYWORDS: wood, fibrillation, deep eutectic solvent, twin-screw extrusion, thermoplastic composite

\section{INTRODUCTION}

The interest in using bio-based materials such as wood and cellulose in composite materials has increased due to the renewability of natural sources and their availability in many forms. $^{1-4}$ Moreover, the extraordinary properties of biocomposites, in addition to their low cost and sustainability, are the main reasons for their further growth in transportation and construction applications as well as consumer goods. ${ }^{5}$ Recently, cellulose fibers with a smaller diameter (e.g., micrometer or nanometer) and an increased length/diameter ratio have been used as reinforcement in polymers to improve their mechanical properties and other behaviors. ${ }^{6}$ Micro- and nanofibrillated cellulose have shown promising properties, resulting in lighter and stronger composites. However, the challenge is to get these particles well dispersed and distributed in the polymer during the compounding process. ${ }^{7-9}$

The pioneering work of cellulose fibrillation was presented by Herrick et al. in 1983, where microfibrillated cellulose was isolated from different types of lignocellulose pulps. ${ }^{10}$ Defibrillation of wood-based materials is usually achieved by chemical treatment such as 2,2,6,6-tetramethyl-1-piperidinyloxy (TEMPO)-oxidation or mechanical disintegration using ultrafine grinding and homogenization processes, or a combination of these methods. ${ }^{11-17}$ These approaches typically use very low fiber concentrations, usually $2 \mathrm{wt} \%$ or less, and they require a high energy consumption. ${ }^{18,19}$

Therefore, recent interest has focused on finding possible fibrillation processes that use higher fiber contents and consume less energy than the current methods. ${ }^{9,20-22}$ Hietala et al. used cellulose pulp and TEMPO-oxidized cellulose pulp with the aim of fibrillating cellulose during the biocomposite compounding process. ${ }^{9}$ The results showed that the use of thermoplastic starch reduced the shear forces and that fibrillation was not efficient. Later, Ho et al. also used an extruder with the aim of fibrillating the cellulose fibers in the extruder. $^{21}$ They showed efficient fibrillation until sizes were reduced to the nanoscale, but the process was repeated several times and the extruder was also cooled to $0{ }^{\circ} \mathrm{C}$, which led to high energy consumption.

Received: October 22, 2020

Revised: December 17, 2020

Published: January 4, 2021 


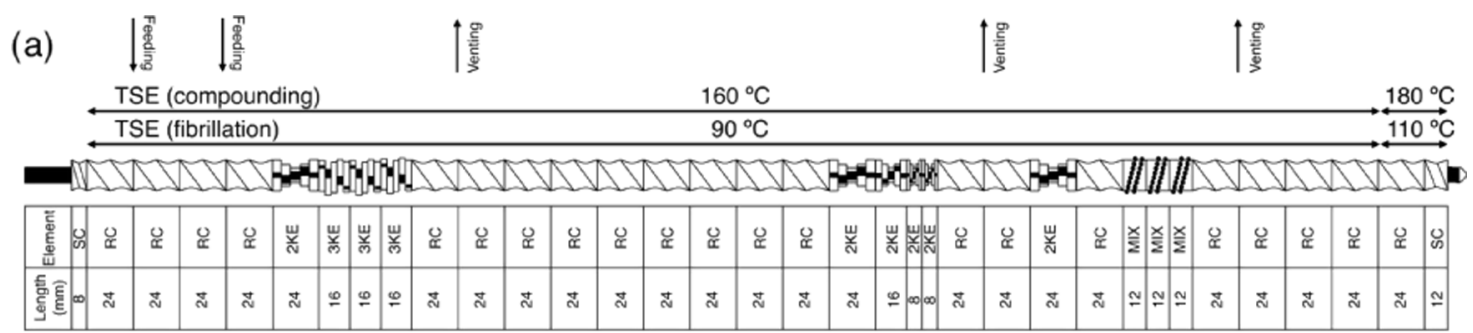

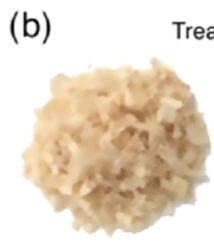

W
Treatment

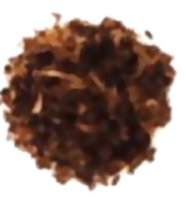

DESW

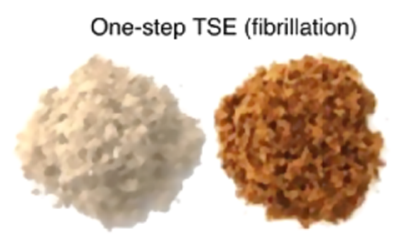

EXW

EXDESW

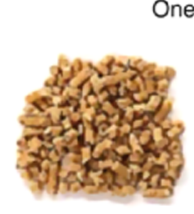

$E X(W-P P)$
One-step TSE (compounding)

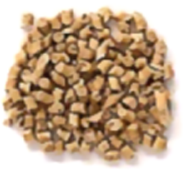

EX(EXW-PP)

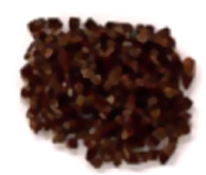

EX(EXDESW-PP)

(c)

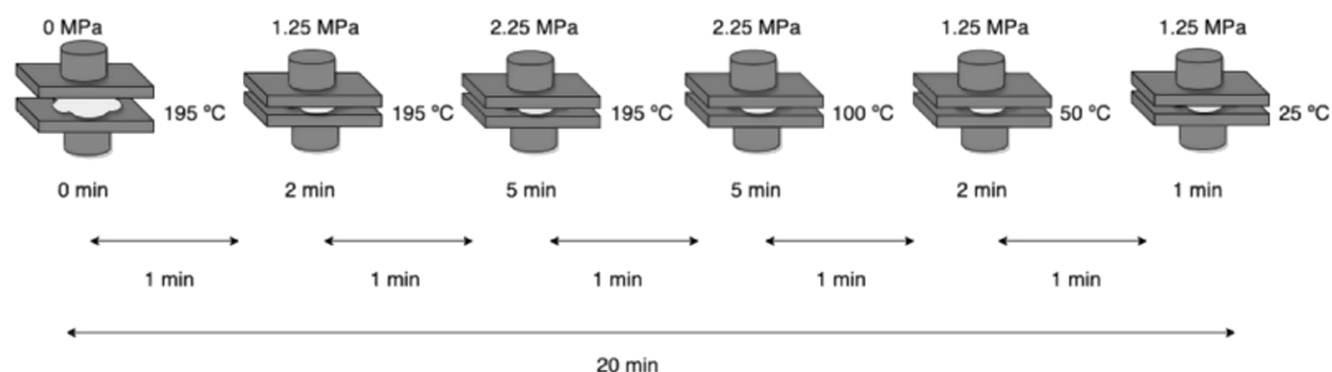

(d)

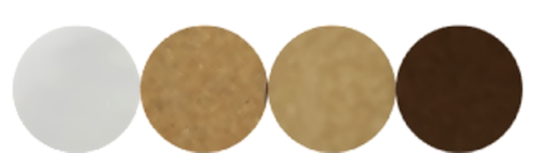

Figure 1. Composite preparation. (a) Twin-screw extruder set-up, screw configuration with short conveying (SC), regular conveying (RC), double flights kneading (2KE), triple flights kneading (3KE), and tooth-mixing (MIX) elements, temperature settings, and feeding and venting zones. (b) Left to right, wood raw material and treated wood raw material before and after treatment, the fibrillated powder, and compounded composite pellet. (c) Time-temperature-pressure protocol of the wood-polypropylene (PP) composite during hot-pressing. (d) Hot-pressed and laser cut samples prepared for melt rheology; from left to right the samples represent neat PP, EX(W-PP), EX(EXW-PP), and EX(EXDESW-PP).

Based on these previous results, the main disadvantages of fibrillation of wood fibers using an extruder are: (i) fiber breakage requires repeated processing steps and (ii) dispersion/distribution of the wood fibrils within a polymer matrix is difficult due to the hydrophilic behavior of wood and the hydrophobic nature of the matrix.

Some previous studies have focused on promoting fiber breakage and improving dispersion using the twin-screw extrusion (TSE) process. ${ }^{23-25}$ Le Ballif and Oksman report that the cellulose fiber length is reduced by $52 \%$ during their extrusion process, and a second extrusion step increases the dispersion of the fibers. ${ }^{23}$ In another study, Hietala and Oksman analyzed the effect of lubricants and different moisture contents of cellulose on fiber breakage and dispersion, and 4-6 wt \% of lubricants improved the performance of pelletized cellulose fibers as reinforcement in polypropylene, resulting in a better dispersion with a higher solid content. ${ }^{25}$

Similarly, Taheri et al. reported the defibrillation of cellulose fibers using one-step twin-screw extrusion. ${ }^{26}$ Cellulose pulp was compounded with hydroxyethyl cellulose (HEC) using one-step TSE to defibrillate the cellulose and produce biocomposites in the same process. However, the increase in the HEC amount caused a lubricating effect and decreased the efficiency of the fibrillation. Consequently, the higher amount of cellulose fiber (lower HEC content) showed a greater degree of fibrillation and fiber breakage due to the incremental shear within extrusion. ${ }^{26}$ The results showed that further consideration of the variables related to the extrusion process and the combination of materials are necessary to improve the fibrillation and compounding process. Therefore, the one-step extrusion process, with a proper extrusion profile, is expected to lead to fibrillation of the wood fibers with low fiber breakage and energy consumption. Moreover, fibrillation can be simultaneously performed with the extrusion of polymeric pellets to produce composite materials. ${ }^{8}$

It is noteworthy that fibrillation of wood and cellulose fibers by different methods such as ultrafine grinding, high-pressure homogenization, or even multistep twin-screw extrusion demands enormous energy. Therefore, reducing the number of processing steps in each of the methods mentioned leads to lower energy consumption. To this purpose, different pretreatment methods can be used to facilitate fibrillation and to decrease energy consumption during the fibrillation process. For instance, enzyme pretreatment of cellulose fibers and chemical pretreatment of wood particles have been shown to enhance fibrillation. ${ }^{27,28}$ Chemical pretreatment can often be performed in water or in solvents, mostly at a low solid content 
Table 1. Sample Coding of Material Compositions and Preparation Methods

\begin{tabular}{|c|c|c|c|c|c|c|c|c|}
\hline \multirow[b]{2}{*}{ sample name } & \multirow[b]{2}{*}{ PP (wt \%) } & \multirow[b]{2}{*}{ W (wt \%) } & \multirow[b]{2}{*}{ EXW (wt \%) } & \multirow[b]{2}{*}{ EXDESW (wt \%) } & \multicolumn{2}{|c|}{ TSE (fibrillation) } & \multicolumn{2}{|c|}{ TSE (compounding) } \\
\hline & & & & & step & energy ( $\mathrm{kW} \mathrm{h} /$ ton $)$ & step & energy ( $\mathrm{kW} \mathrm{h} /$ ton $)$ \\
\hline $\mathrm{PP}$ & 100 & 0 & 0 & 0 & 0 & $\mathrm{~N} / \mathrm{A}$ & 0 & $\mathrm{~N} / \mathrm{A}$ \\
\hline $\mathrm{W}$ & 0 & 100 & 0 & 0 & 0 & $\mathrm{~N} / \mathrm{A}$ & 0 & $\mathrm{~N} / \mathrm{A}$ \\
\hline EXW & 0 & 0 & 100 & 0 & 1 & 1058 & 0 & $\mathrm{~N} / \mathrm{A}$ \\
\hline EXDESW & 0 & 0 & 0 & 100 & 1 & 802 & 0 & $\mathrm{~N} / \mathrm{A}$ \\
\hline $\mathrm{EX}(\mathrm{W}-\mathrm{PP})$ & 50 & 50 & 0 & 0 & 0 & $\mathrm{~N} / \mathrm{A}$ & 1 & 767 \\
\hline EX(EXW-PP) & 50 & 0 & 50 & 0 & 1 & $\mathrm{~N} / \mathrm{A}$ & 1 & 643 \\
\hline EX(EXDESW-PP) & 50 & 0 & 0 & 50 & 1 & $\mathrm{~N} / \mathrm{A}$ & 1 & 571 \\
\hline
\end{tabular}

(fiber wt \%). Thus, the dry matter content of the pretreatment, simplicity of the treatment, cost, and toxicity of materials are the factors that need to be considered when chemical pretreatment is conducted.

Recently, interesting studies in which green solvent systems, termed as deep eutectic solvents (DESs), used as pretreatment to reduce the interfibrillar bonding within lignocellulosic materials have been reported. ${ }^{29-32}$ DESs typically consist of a mixture of two components (hydrogen bond acceptor and hydrogen bond donor), which form a eutectic solution with a considerably lower melting temperature than that of the original individual constituents. DESs possess many appealing characteristics such as low toxicity, renewability, and biodegradability as well as low costs. ${ }^{33}$

In this work, the first goal was to examine if fibrillation of wood sawdust (W) with a high solid content (40 wt \%) is possible using the twin-screw extrusion process. Furthermore, if a green and low-cost deep eutectic solvent can be used as a pretreatment to enhance the fibrillation since it is known that this treatment softens/degrades the lignin polymer in wood. The secondary goal was to use this fibrillated wood as reinforcement in biocomposites. We also compared these biocomposites with composites where wood sawdust and nontreated wood were used in the same concentration. The obtained composites were hot-pressed to observe how the fibrillation as well as the compounding processes affected the fiber and composite properties. As a repeated number of extrusions will cause fiber breakage and decrease the mechanical properties, the aim was to achieve the fibrillation and composites using the least possible number of extrusion steps.

\section{MATERIALS AND METHODS}

Materials. Dry wood sawdust (W), which is generally used in animal beds (Pölkky Oy, Kuusamo, Finland), was used as the raw material for fibrillation in this work. The chemical composition of the raw material was measured using the TAPPI-T 222 standard. The sawdust contained 58.5 wt \% cellulose, 28.1 wt \% lignin, $12.5 \mathrm{wt} \%$ hemicellulose, and $0.9 \mathrm{wt} \%$ inorganics. Potassium carbonate (Honeywell, Seelze, Germany) and glycerol (VWR chemicals, Leuven, Belgium) were used in the preparation of a deep eutectic solvent (DES) for the pretreatment of wood sawdust. High-performance polypropylene (Braskem Europe $\mathrm{GmbH}$, Frankfurt, Germany) with a melt flow index of $25 \mathrm{~g} / 10 \mathrm{~min}$ at $230{ }^{\circ} \mathrm{C}$ was used as the polymer matrix for the composites. Deionized water was used to wash the wood after DES treatment.

Deep Eutectic Solvent Treatment. A mixture of potassium carbonate (as a hydrogen bond acceptor) and glycerol (as a hydrogen bond donor) was used for the pretreatment of wood sawdust. The treatment was performed with a DES molar ratio of 1:5 (acceptor/ donor) and a wood consistency of $3 \%$ at $100{ }^{\circ} \mathrm{C}$ for $18 \mathrm{~h}$. The pretreated wood material was washed and vacuum-filtered to remove the remaining chemicals from treated wood sawdust following a procedure described in an earlier work by Suopajärvi et al. ${ }^{34}$

Extrusion Process and Sample Preparation. The fibrillation of $\mathrm{W}$ and treated deep eutectic solvent-treated wood sawdust (DESW) was performed in a one-step TSE process. The solid content of the W and DESW was controlled at approximately $40 \mathrm{wt} \%$ before the extrusion process and increased to approximately $95 \mathrm{wt} \%$ ((EXW) and EXDESW) after the fibrillation step because some water is evaporated during the process. The fibrillation step was performed using a co-rotating twin-screw extruder ZSK-18 MEGALab (Coperion W\&P, Stuttgart, Germany) with a screw speed of $200 \mathrm{rpm}$. The fibrillation temperature was set to $90{ }^{\circ} \mathrm{C}$ for seven processing zones and increased to $110{ }^{\circ} \mathrm{C}$ at the end zone. The fibrillation step was performed without the die tool, to reduce the pressure at the end of the process and to avoid blocking the die by dry formed powder. Two atmospheric vents and one vacuum vent were used to remove the moisture and steam (see Figure 1a).

The fibrillated wood was reprocessed with $\mathrm{PP}$, and the proportion of wood/fibrillated wood and the polymer was 50/50 for all composites (Table 1$)$. The compounding of the primary wood-PP composite EX(W-PP) was performed in one-step TSE and the other composites were prepared in two steps: the fibrillation step of wood followed by compounding of the wood fibrils with PP composites. The compounding step of wood and PP was performed using the same extruder and the same screw speed. The compounding temperature was set to $160{ }^{\circ} \mathrm{C}$ for all seven processing zones and increased to $180^{\circ} \mathrm{C}$ at the die. A circular die with a diameter of $5 \mathrm{~mm}$ was used for the compounding step. The residence time of materials in the extruder for fibrillation and compounding steps was approximately 85-95 s. The temperature profile for fibrillation and compounding steps, screw elements such as short conveying (SC), regular conveying $(\mathrm{RC})$, double flights kneading $(2 \mathrm{KE})$, triple flights kneading (3KE), and tooth mixing (MIX) elements are shown in Figure 1a. The specific energy consumption (SEC) of the extrusion process was calculated by eq 1 for several samples as follows ${ }^{35}$

$$
\operatorname{SEC}\left(\frac{\mathrm{KW} \mathrm{h}}{t}\right)=\frac{N \cdot P_{\max }}{N_{\max } \cdot M_{\mathrm{d}} \cdot Q}
$$

where $N$ is the screw speed (200 rpm), $N_{\max }$ is the maximum speed of the extruder $(1200 \mathrm{rpm}), P_{\max }$ is the maximum motor power (10 $\mathrm{KW}), M_{\mathrm{d}}$ is the torque\% (30-45\%), and $Q$ is the material dry matter feeding rate $(0.47-1.1 \mathrm{~kg} / \mathrm{h})$.

After the compounding of wood fibrils and PP, the pellets with a moisture content less than $2 \mathrm{wt} \%$ (Figure $1 \mathrm{~b}$ ) were compression molded between aluminum plates covered with Teflon films using a laboratory press (LabEcon 300, Fontijne Press, Vlaardingen, the Netherlands). The pellets were uniformly distributed on a Tefloncovered cylindrical frame with a diameter of $10 \mathrm{~cm}$ and then the pressure was applied. Compression molding was accomplished using a heating-cooling protocol under a pressure of $1.25 \mathrm{MPa}$ at $195{ }^{\circ} \mathrm{C}$ for $2 \mathrm{~min}$, followed by an increase in the pressure to $2.25 \mathrm{MPa}$ at $195^{\circ} \mathrm{C}$ for $5 \mathrm{~min}$, and then $2.25 \mathrm{MPa}$ at $100{ }^{\circ} \mathrm{C}$ for another $5 \mathrm{~min}$, continuing on with $1.25 \mathrm{MPa}$ at $50{ }^{\circ} \mathrm{C}$ for $2 \mathrm{~min}$, and ultimately $1.25 \mathrm{MPa}$ at 25 ${ }^{\circ} \mathrm{C}$ for $1 \mathrm{~min}$ (Figure 1c). The compression-molded plates were cut into test specimens using a laser (Epilog Laser Fusion, Colorado) with a resolution of $300 \mathrm{dpi}$ and a vector speed of $8 \%$. The prepared 
Table 2. Fiber Width and Mass Proportion of Fractions from the Tube Flow Fractionation Test and Image Processing for EXW and EXDESW Samples ${ }^{a}$

\begin{tabular}{|c|c|c|c|c|c|c|c|c|c|c|}
\hline \multirow[b]{2}{*}{ sample name } & \multicolumn{2}{|c|}{ fraction 1} & \multicolumn{2}{|c|}{ fraction 2} & \multicolumn{2}{|c|}{ fraction 3} & \multicolumn{2}{|c|}{ fraction 4} & \multicolumn{2}{|c|}{ fraction 5} \\
\hline & fiber width ${ }^{b}$ & $(\%)$ & fiber width $^{b}$ & $(\%)$ & fiber width $^{b}$ & $(\%)$ & fiber width $^{b}$ & $(\%)$ & fiber width ${ }^{b}$ & $(\%)$ \\
\hline EXW & $20.4(0.9)$ & 8.5 & $16.7(1.9)$ & 20.7 & $12.6(1.1)$ & 43.9 & $7.4(0.2)$ & 22.3 & $2.6(0.3)$ & 4.6 \\
\hline EXDESW & $20.5(0.5)$ & 9.3 & $15.4(1.3)$ & 18.4 & $11.2(0.9)$ & 43.6 & $6.9(0.5)$ & 23.4 & $2.9(0.2)$ & 5.3 \\
\hline
\end{tabular}

${ }^{a}$ The values in parentheses are standard deviations. ${ }^{b}$ The average fiber width $(\mu \mathrm{m})$ was calculated by image processing.

specimens (cut with a laser machine) with a diameter of $10 \mathrm{~mm}$, a length of $80 \mathrm{~mm}$ and a width of $5 \mathrm{~mm}$, and a diameter of $25 \mathrm{~mm}$ were used for the contact angle test and tensile and melt rheology measurements (Figure 1d), respectively. The prepared specimens (for tensile test) were stored for 3 days under testing conditions at a relative humidity $(\mathrm{RH})$ of $50 \%$ at $23{ }^{\circ} \mathrm{C}$.

\section{CHARACTERIZATION}

Fractionation. The size reduction of the extruded materials (EXW and EXDESW) was studied using a tube flow fractionator device (Valmet Automation Oy, Kajaani, Finland) equipped with IMG image analyzer software. The fractionator apparatus was equipped with a high-speed CCD camera, and the fiber images (around 2000 images) were captured during a very small timescale (milliseconds) to investigate the size reduction. ${ }^{36}$ The extracted fibers were diluted in water to $0.3 \mathrm{wt} \%$ prior to each tube flow fractionation test, and the data were recorded in five different fractions (attached as the Supporting Video), starting from large fibers (first fraction) and ending with the smallest fibers (fifth fraction).

Optical Microscopy. Optical microscopy (OM) (Leica MZ FL III, Leica Camera AG, Wetzlar, Germany) was used to study the structure of W, EXW, and EXDESW before and after the one-step TSE process (fibrillation). The samples were diluted in water to $0.1 \mathrm{wt} \%$ prior to the study.

Field Emission Scanning Electron Microscopy (FESEM). Field emission scanning electron microscopy (FE-SEM) (ZEISS ULTRA plus FE-SEM, Carl Zeiss AG, Oberkochen, Germany) was used to study the microstructure of EXW and EXDESW to understand the effect of the treatment method on fibrillation. The collected fourth fraction and a mixture of five fractions after the fractional test were studied using FE-SEM to compare the morphological change for the processed wood material after extrusion (EXW and EXDESW). The collected materials were diluted in water to 0.01 wt $\%$ and vacuumfiltered through a Nuclepore Track-Etch membrane with a pore size of $0.2 \mu \mathrm{m}$ (Whatman, U.K.), then immediately frozen in liquid nitrogen and freeze-dried for $24 \mathrm{~h}$. The samples were mounted on sample holders and platinum-coated before FESEM to avoid charging. An acceleration voltage of $5 \mathrm{kV}$ was used. FE-SEM was also used to study the extent of the wood fiber dispersion from the cross sections of wood-PP composites (pellets before the hot-pressing). FE-SEM images were also provided from the cross sections of the fractured specimen after the tensile test to understand the fiber-polymer interfaces.

Fourier Transform Infrared Spectroscopy (FTIR). Fourier transform infrared spectroscopy (FTIR) was used to determine the chemical composition of the treated and untreated samples after one-step TSE (fibrillation). The FTIR of dried EXW and EXDESW powder (Figure 1b) was measured using an FTIR-Bruker (Optik GmbH, Ettlingen, Germany) at $4000-400 \mathrm{~cm}^{-1}$ wavenumbers with a resolution of $4 \mathrm{~cm}^{-1}$, averaged over 40 scans.
Rheometry. Rheological measurements of aqueous dispersions (2 wt \%) of untreated and DES-treated wood sawdust after TSE (EXW, EXDESW) were performed using a TA Instrument Discovery HR-1 Hybrid Rheometer (New Castle, $\mathrm{DE})$. The flow behavior of the samples under strain-controlled mode was measured at $25{ }^{\circ} \mathrm{C}$ using bob and cup accessories and with diameters of 27.97 and $30.35 \mathrm{~mm}$, respectively. The rheological data was reproduced using three different gaps (1.5, 2.0. and $2.5 \mathrm{~mm}$ ), and the gap of $1.5 \mathrm{~mm}$ was chosen as the reference gap since no wall-slip effect was observed. Rheological data were provided at shear rates of $0.1-1000$ $\mathrm{s}^{-1}$ (within $20 \mathrm{~min}$ ) and water evaporation was also controlled using a standard hood cover for all experiments. The rotational measurements were performed under a controlled ascending and descending shear rate $(10 \mathrm{~min}$ for ramping up and $10 \mathrm{~min}$ for ramping down) to show the suspension stability at shear rate intervals.

Melt rheology of the wood-PP composites was measured using the same rheometer equipped with a plate and plate accessories $(25 \mathrm{~mm}$ diameter $)$ at $190{ }^{\circ} \mathrm{C}$ in both a steady-state shear rate $\left(1-1000 \mathrm{~s}^{-1}\right)$ and dynamic mode. The rheometer was operated at a constant frequency of $1 \mathrm{~Hz}$ for the strain sweep test and a constant strain of $2 \%$ for the oscillatory sweep test. The compression molded composite samples (Figure 1d) were sheared for $5 \mathrm{~min}$ to ensure temperature compatibility between the samples and rheometer plates. The gap between the rheometer plates was set at $1 \mathrm{~mm}$ and the initial force of the rheometer was between 0.1 and $1.0 \mathrm{~N}$.

Contact Angle. The static wettability of the prepared wood-PP composites was observed using a Drop Shape Analyzer DSA100 instrument (Krüss GmbH, Hamburg, Germany) equipped with a high-speed frame camera (360 fps). A water droplet with a volume of $4 \mu \mathrm{L}$ was loaded on the surface of the different composites, and the static contact angle was measured (three times per sample) within $60 \mathrm{~s}$.

Mechanical Testing. The tensile properties of the woodPP composite materials were measured using a universal testing machine (Zwick, Ulm, Germany) equipped with a $1 \mathrm{kN}$ load cell, and all tests were performed following the DIN EN ISO 527-1 standard. The compression-molded composite specimens with a $5 \mathrm{~mm}$ width, a $1.15-1.43 \mathrm{~mm}$ thickness, and an $80 \mathrm{~mm}$ length were mechanically tested. The thickness of each specimen was determined by averaging the thicknesses of three random locations on the specimen, using a micrometer Rhopoint instrument (Bexhill-on-Sea, U.K.). The specimens were stored in $50 \% \mathrm{RH}$ at $23{ }^{\circ} \mathrm{C}$ in the measurement environment. The gauge length was set to $30 \mathrm{~mm}$, the strain rate was $3 \mathrm{~mm} / \mathrm{min}$, and the samples were preloaded to $1 \mathrm{~N}$. The results are presented as an average of six measurements. To calculate the elastic modulus, the tensile properties were measured using a universal testing machine with a $5 \mathrm{kN}$ load cell, Shimadzu AG-X (Kyoto, Japan) with a video extensometer for monitoring the strain, following the ASTM D-638 standard. The sample size was approximately $30 \mathrm{~mm}$ long, 5 


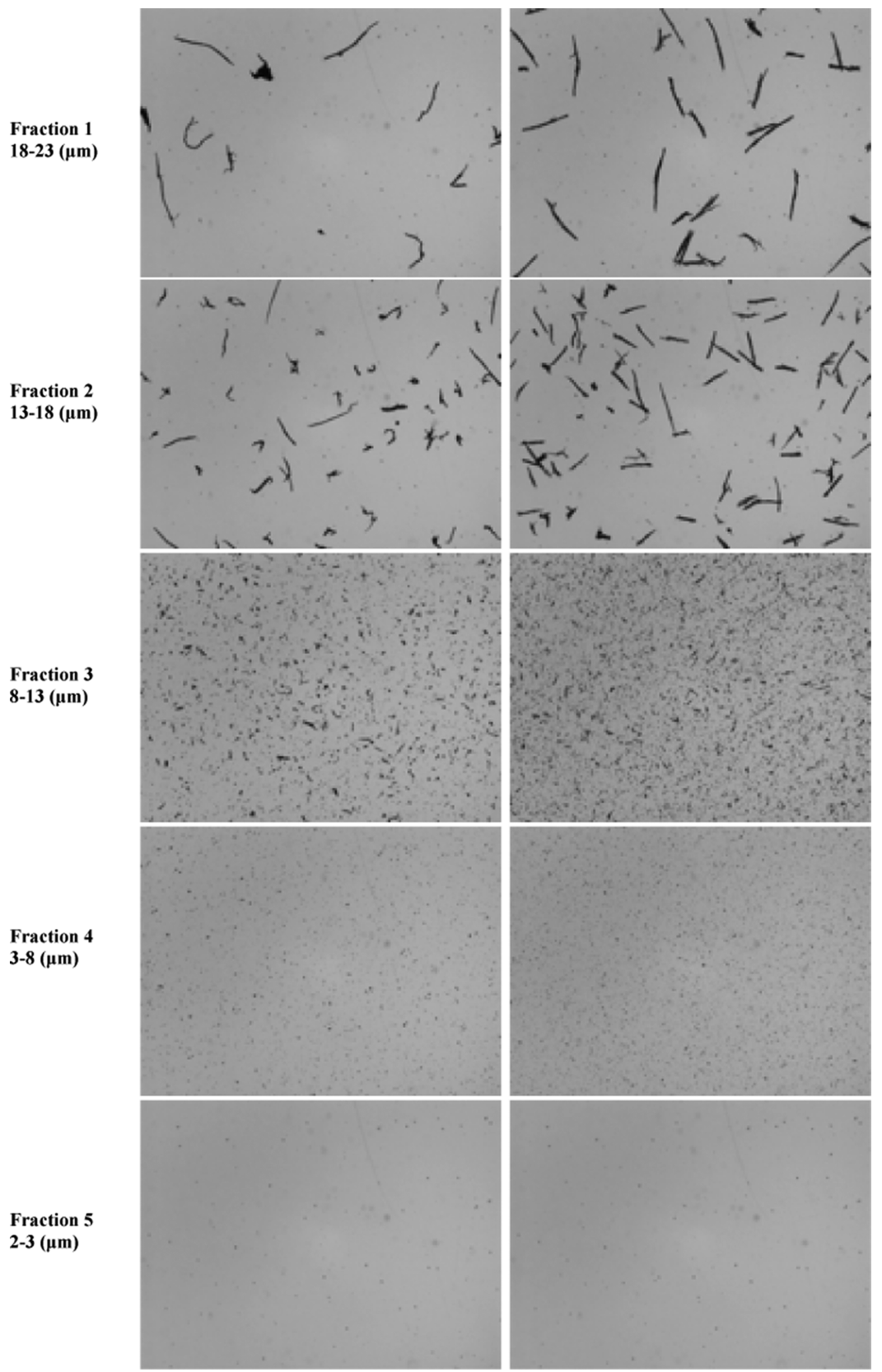

Figure 2. Micrographs of the tube flow fractionation test of EXW (left images) and EXDESW (right images) in the 0.3 wt \% water dispersion with five different fiber width fractions. Each row is related to one specific fraction. (Video is available in the Supporting Information).

$\mathrm{mm}$ wide, $1 \mathrm{~mm}$ thick, and a gauge length of $20 \mathrm{~mm}$ was used with a strain rate of $2 \mathrm{~mm} / \mathrm{min}$. Five measurements were made per material.

\section{RESULTS AND DISCUSSION}

Fiber Morphology. The morphology of the extruded wood (EXW) and extruded DES-treated wood (EXDESW) was studied using a fractional test, OM, and FE-SEM. The numerical data for the different fractions from the flow fractionator and image processing are listed in Table 2. The micrographs of the five different fractions for EXW and EXDESW showing the effect of extrusion on fiber fibrillation are shown in Figure 2 and a Supporting Information Video. The micrographs clearly indicate that the fibrillation step resulted in fiber size reduction and the samples contained a notable amount of small fiber fragments (fractions 3-5).
The optimal extrusion profile and defibrillation can be derived from fractions with a low proportion of large fiber constituents. The first two fractions had a relatively low percentage of the material compared to the larger percentage in the last three fractions. The total amount of the material in the third and fourth fractions for EXW and EXDESW was approximately $65 \%$. Based on the fractional data, the fibrillation step resulted in a significant reduction in the fiber size and increased the proportion of the thin fibers.

The larger content of the material in the fourth and fifth fractions compared to the untreated sample confirmed that the DES treatment promoted fibrillation and efficiently decreased the particle size. The average particle lengths of EXW and EXDESW were also recorded from the fractionator and were around $489( \pm 14)$ and $541( \pm 18) \mu \mathrm{m}$, respectively. 

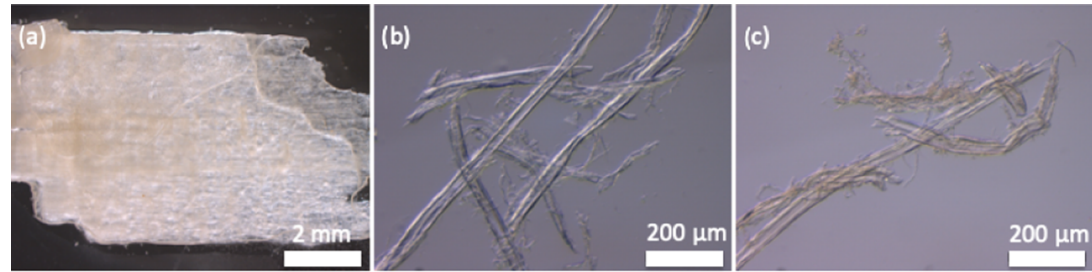

Figure 3. Optical microscopy of the wood sawdust before and after TSE. (a) Original wood sawdust particle (W), (b) extruded wood sawdust (EXW), and (c) extruded and DES-treated wood sawdust (EXDESW).
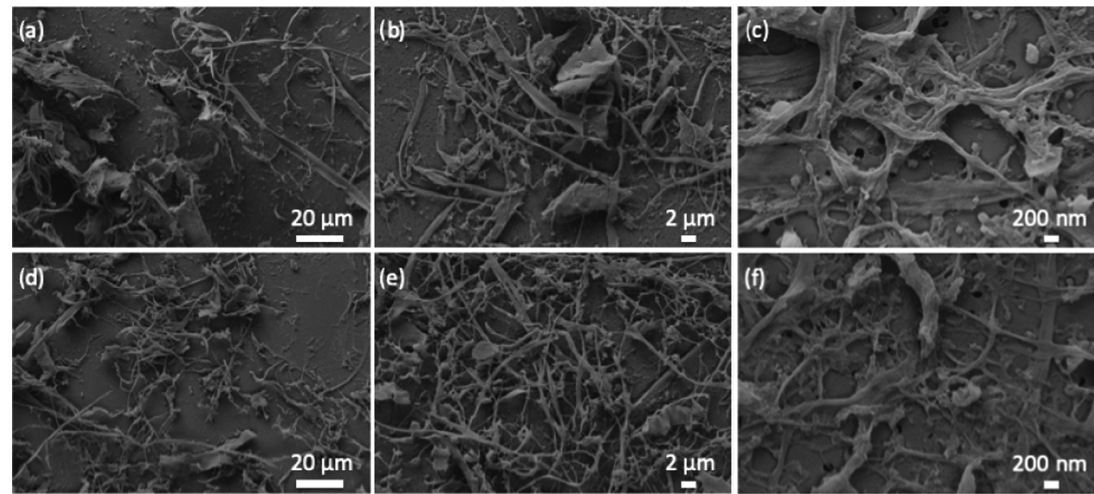

Figure 4. FE-SEM images of DES-treated and untreated wood sawdust processed by one-step TSE. (a) EXW, (b) EXW mixed with all fractions after fractional testing, (c) EXW sampled from the fourth fraction (Table 2), (d) EXDESW, (e) EXDESW mixed with all fractions after fractional testing, and (f) EXDESW sampled from the fourth fraction (Table 2).

The corresponding average aspect ratio $(1 / \mathrm{d})$ was 45 for the untreated wood and 56 for the DES-treated wood. This result indicates that the DES treatment resulted in less fiber breakage compared to the untreated reference. The last two fractions (fractions 4 and 5) represent the finest diameter fibers of the samples, and they were further analyzed by optical microscopy and FE-SEM. Optical microscopy was used to investigate the size alteration of wood particles during the extrusion step. As shown in Figure 3, OM confirmed a clear particle size reduction from a millimeter scale $(\mathrm{W})$ to a micrometer scale (EXW and EXDESW). These observations in size alteration (both width and length) of $\mathrm{W}$ agree with previous results obtained with the extruder process. ${ }^{21,22}$ The size reduction of the EXW and EXDESW was also in agreement with fractional data, as presented in Table 2.

The FE-SEM images of EXW and EXDESW are presented in Figure 4, and they support the findings shown in the optical micrographs and fractionation data. In addition, FE-SEM images show some large particles attributed to nonfibrillated wood litter. Overall, both EXW and EXDESW contained elongated fibrils and larger fibril aggregates.

FE-SEM of EXDESW (Figure 4d,e) shows a greater degree of fibrillation with a lower number of large particles compared to the untreated sample. Unlike EXW, the small round particles were absent for EXDESW (Figure 4f), which is likely related to a lower degree of fiber breakage. Based on the FESEM observations, the fiber widths of untreated and DEStreated $\mathrm{W}$ were in the range of $35-45 \mu \mathrm{m}$ (with some large particles) and 40-50 $\mu \mathrm{m}$ (with fewer large particles), respectively. However, the fiber length of the DES-treated sample was greater than that of the untreated $\mathrm{W}$, which agrees with the aspect ratio of the fibers from the fractional test. Thus, the changes in the particle morphology of the extruded samples confirmed that the deep eutectic solvent treatment promoted wood fibrillation and caused less fiber breakage.
However, the DES treatment also resulted in a color change, where the material had a brown color after the treatment (Figure 1b).

Chemical Composition. FTIR spectra of EXW and EXDESW were examined to explain the possible chemical changes caused by the DES treatment (Figure 5). The strong

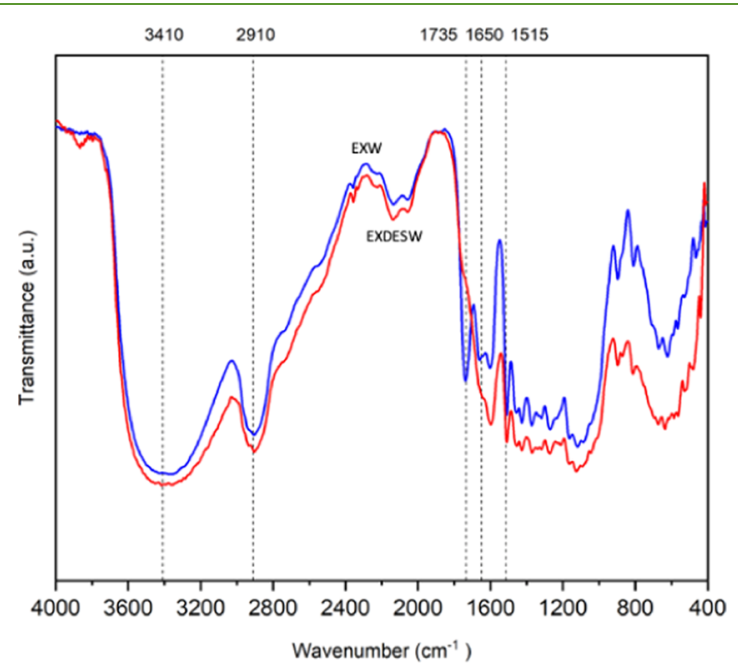

Figure 5. FTIR spectra of untreated (EXW) and DES-treated wood sawdust (EXDESW).

and broad band at $3410 \mathrm{~cm}^{-1}$ was related to the $-\mathrm{OH}$ stretching of hydroxyl groups and was observed in both samples. The peak at $2910 \mathrm{~cm}^{-1}$ for both samples was related to the $\mathrm{C}-\mathrm{H}$ stretching of alkyl groups. The main change after the DES treatment was related to the $\mathrm{C}=\mathrm{O}$ vibrations of the carbonyl group at $1735 \mathrm{~cm}^{-1}$. The carbonyl group often exists in the lignin structure and the absence of this band is evidence 
(a)

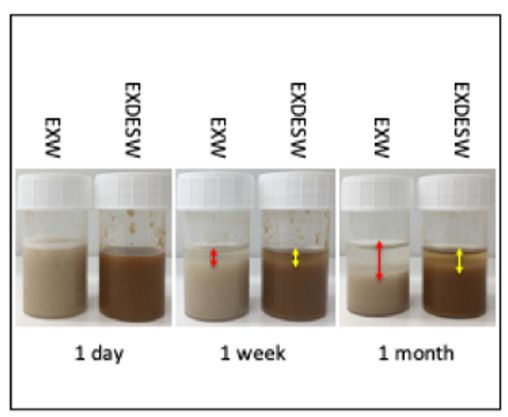

(c)

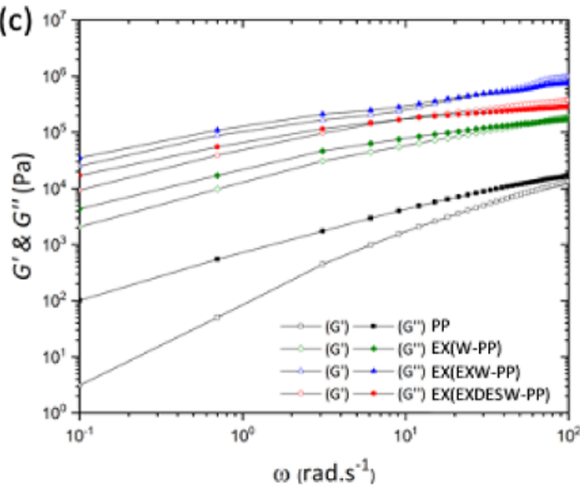

(b)

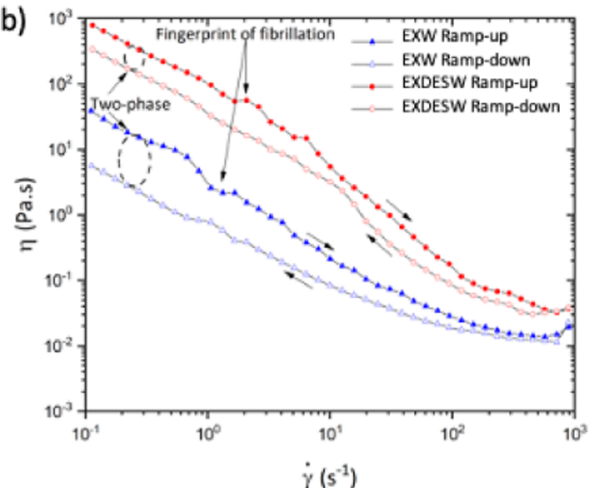

(d)

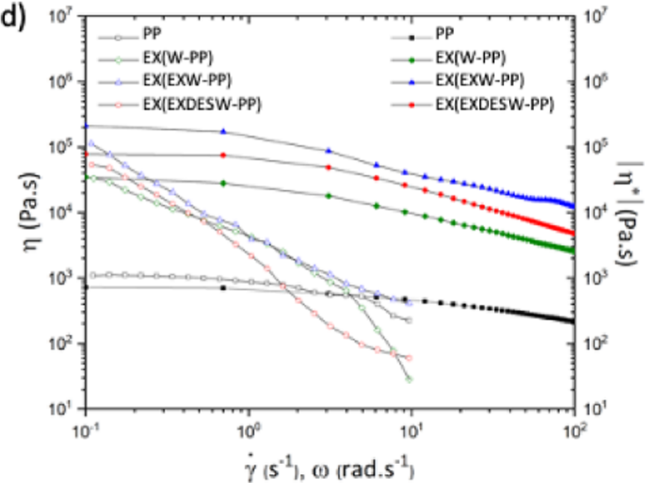

Figure 6. Suspension stability and rheology of extruded wood sawdust, and melt rheology of the wood composite. (a) Stability of EXW and EXDESW suspensions (2\%) as a function of time, (b) ascending/descending steady-state shear rate versus viscosity of EXW (2 wt \%) and $\operatorname{EXDESW}(2 \mathrm{wt} \%)$ at $25^{\circ} \mathrm{C}$, (c) frequency sweep test of molten samples (Figure 1d) in a constant strain of $1 \%$ at $190{ }^{\circ} \mathrm{C}$, and (d) comparison of steady-state rheology (open symbols) and dynamic rheology (solid symbols) of PP and composites due to the Cox-Merz rule at $190{ }^{\circ} \mathrm{C}$.

of rupturing of the lignin side chains. ${ }^{37}$ In addition, a reduction in the $\mathrm{H}-\mathrm{OH}$ peak intensity at $1650 \mathrm{~cm}^{-1}$ was observed. This peak is likely related to changes in the hemicellulose structure in the samples. ${ }^{38}$ Moreover, the reduction of the peak intensity at $1515 \mathrm{~cm}^{-1}$ was related to the $\mathrm{C}=\mathrm{C}$ vibrations of aromatic groups and confirmed the rupture of lignin. Therefore, the brownish color of the DES-treated sample might be associated with the degradation of lignin and hemicellulose within the DES treatment. The yellowish color of DES-treated rice straw has also been reported. ${ }^{39}$

Rheological Properties. Rheological properties of the samples were studied in two parts: (i) suspension rheology to understand the fibrillation of the wood sawdust after the DES treatment and extrusion, and (ii) melt rheology of the composites.

The EXW (2 wt \%) and EXDESW (2 wt \%) were first dispersed in deionized water to address the suspension rheology. As shown in Figure 6a, the stability of the suspensions was monitored for 1 month, wherein the DEStreated and extruded suspension (EXDESW) showed better stability and less sedimentation than the untreated (EXW) suspension. The rheology of the dispersions for both suspensions showed the fibrillation fingerprint (depicted with arrows in Figure 6b) at intermediate shear rates from 1 to 10 $\mathrm{s}^{-1}$. Moreover, the viscosity and fibrillation plateau of the DEStreated suspension was 25 times higher than that of the untreated suspension, confirming a more efficient fibrillation (networks) of EXDESW. This result is also supported by the results of the fractional test, OM, and FE-SEM. The two-phase hysteresis of the ramp-up/ramp-down data at low shear rates reveals the stability of the dispersed samples. ${ }^{40}$ The EXDESW showed less hysteresis at a low shear rate than EXW, which is also supported by the visual observations (Figure 6a).

The melt rheology of neat PP and wood-PP composites was measured as a function of the frequency at a constant $1 \%$ strain. The frequency sweep data of neat PP was lower at all frequencies. As the loss modulus $\left(G^{\prime \prime}\right)$ of neat PP was higher than the storage modulus $\left(G^{\prime}\right)$, the liquidlike behavior of neat $\mathrm{PP}$ was confirmed within the whole frequency range and the wood-PP composites all had a higher loss and storage modulus than neat PP (Figure 6c). However, the EX(W-PP) composite exhibited a liquidlike behavior at low and intermediate frequency regions, with an inflection at a frequency of 50 $(\mathrm{rad} / \mathrm{s})$. The untreated sample EX(EXW-PP), which was extruded in two steps (fibrillation and compounding), showed the highest frequency sweep trend and the $G^{\prime}-G^{\prime \prime}$ inflection occurred at an intermediate frequency of $20(\mathrm{rad} / \mathrm{s})$. In contrast, the frequency sweep trend of the DES-treated and two-step extruded sample EX(EXDESW-PP) showed a $G^{\prime}-G^{\prime \prime}$ inflection at a lower frequency of $5(\mathrm{rad} / \mathrm{s})$.

The inflection represents a higher degree of formation of fiber networks present at low frequencies. According to fiber ruptures for the EX(EXW-PP) sample, it can be expected that the $G^{\prime}-G^{\prime \prime}$ inflection will shift at higher frequencies. Therefore, the higher $G^{\prime}$ and $G^{\prime \prime}$ moduli of the EX(EXW-PP) sample compared to those of EX(EXDESW-PP) might be due to very small particles or fiber breakage, as observed in the fractional tests, OM, and FE-SEM.

In general, the complex viscosity $|\eta *(\omega)|$ from dynamic testing (oscillatory) can be compared with the shear viscosity $\eta(\dot{\gamma})$ from steady-state testing (rotational) at low shear rates and low frequencies, which is the so-called Cox-Merz principle. ${ }^{41}$ The plotted data of neat PP and the various composites at $\left|\eta^{*}(\omega)\right|$ 


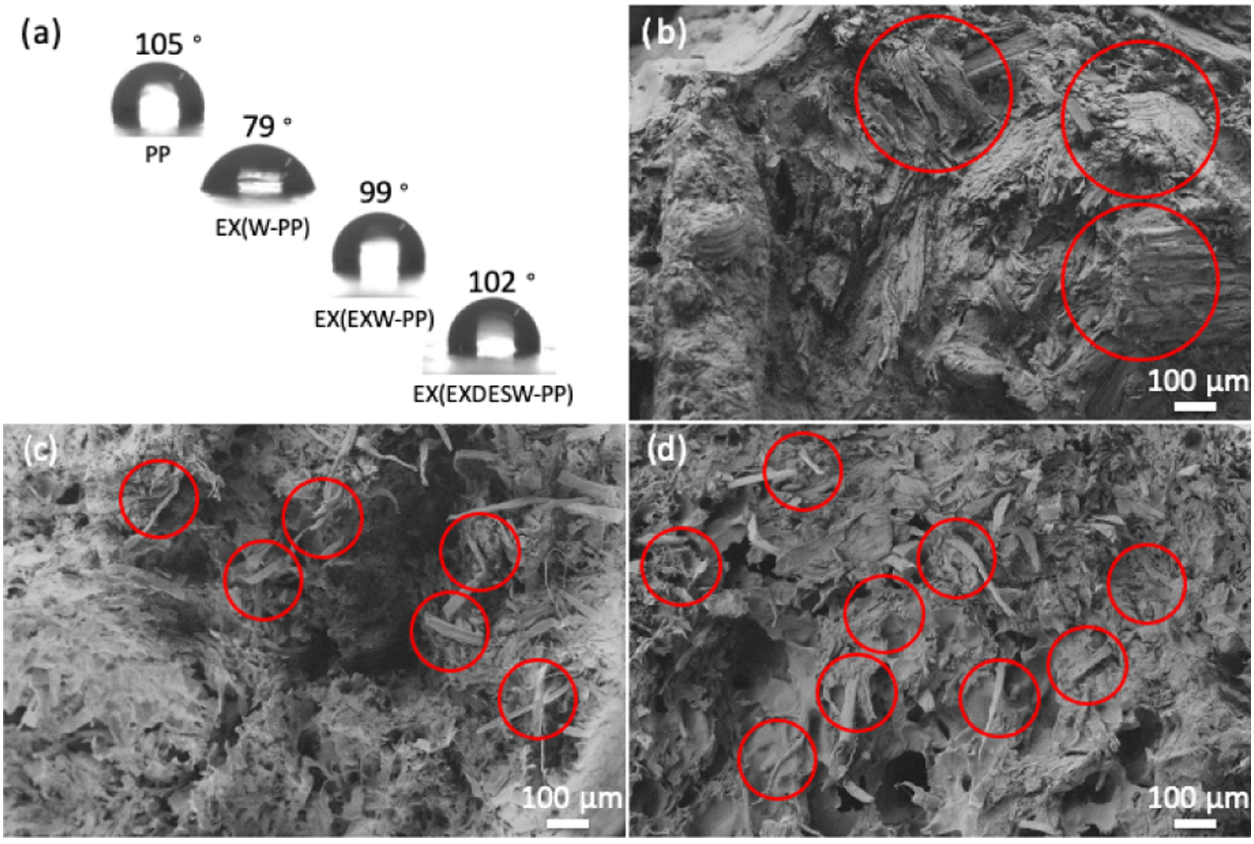

Figure 7. (a) Contact angle of PP and the prepared wood-PP composites and FE-SEM images of fractured cross sections of the wood-PP composites after the extrusion process (before compression molding) showing the dispersion and distribution of the wood in the PP matrix: (b) EX(W-PP), (c) EX(EXW-PP), and (d) EX(EXDESW-PP).
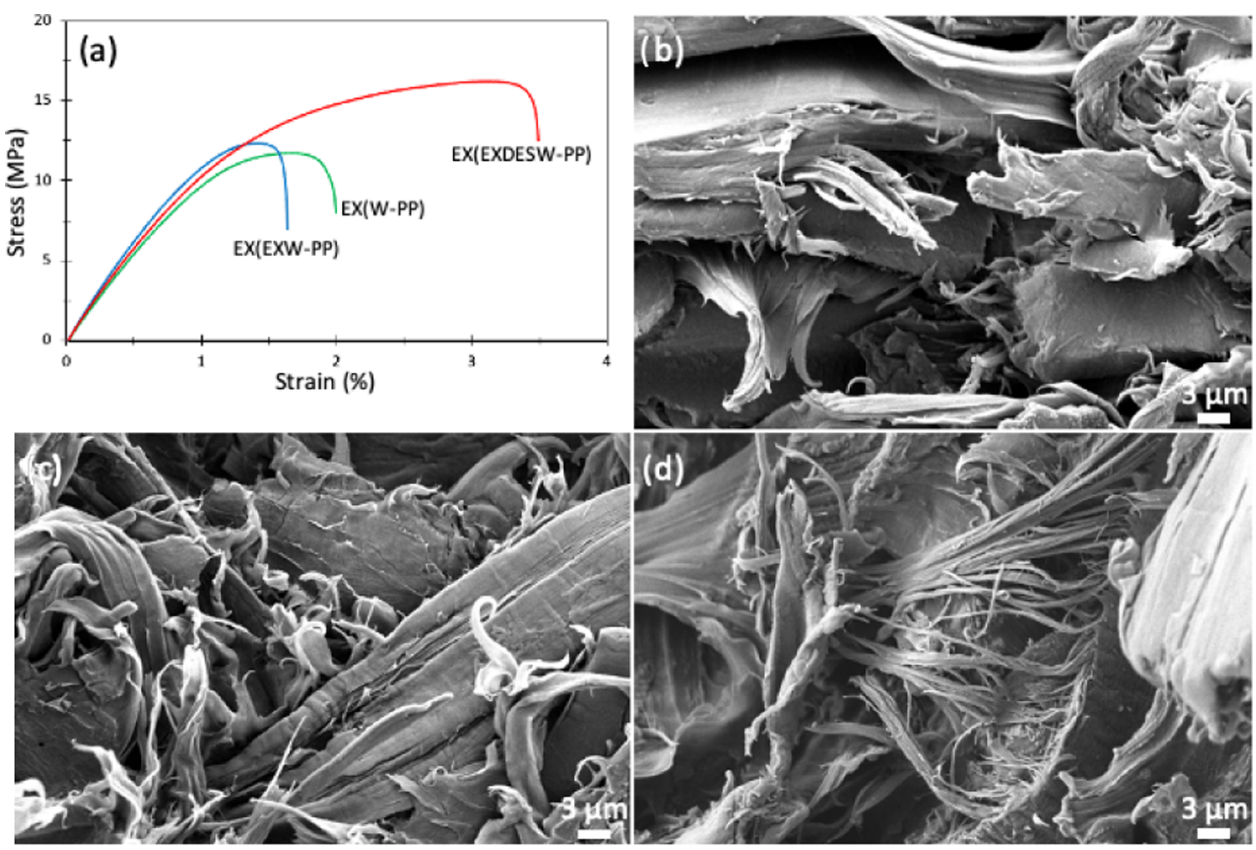

Figure 8. Properties of prepared wood-PP composites. (a) Typical stress-strain curves of the materials and FE-SEM images of fractured tensile specimen cross sections of different composites (b) EX(W-PP), (c) EX(EXW-PP), and (d) EX(EXDESW-PP).

$=\eta(\dot{\gamma})$ indicate an overlapping of data for neat PP, as shown in Figure 6d. However, this rule is not applicable at high fiber contents. ${ }^{42}$ Therefore, a combination of dynamic and steadystate data demonstrates that the different composites with a high fiber content (50\%) do not follow the Cox-Merz principle for complex viscosity, in agreement with other work, ${ }^{43}$ but provides a better overlap at very low shear rates or frequencies of $0.1\left(\mathrm{~s}^{-1}\right)$ or $0.1(\mathrm{rad} / \mathrm{s})$, respectively. The main reasons for the steady-state and dynamic data deviations might be related to the presence of intra- and intermolecular hydrogen bonds or the negative charges of the wood particles in the PP matrix.

Contact Angle. The contact angles of neat PP and the composites were also studied, as shown in Figure 7a. The neat PP represents the highest contact angle of $105 \pm 1^{\circ}$ measured from both sides of the sample. The contact angle of the directly compounded sawdust polypropylene composite EX(W-PP) dropped to $79 \pm 2^{\circ}$, which is related to the hydrophilicity of the wood material. However, interestingly, the contact angles of the composites with the fibrillated wood materials EX(EXW-PP) and EX(EXDESW-PP) increased to $99 \pm 3^{\circ}$ 

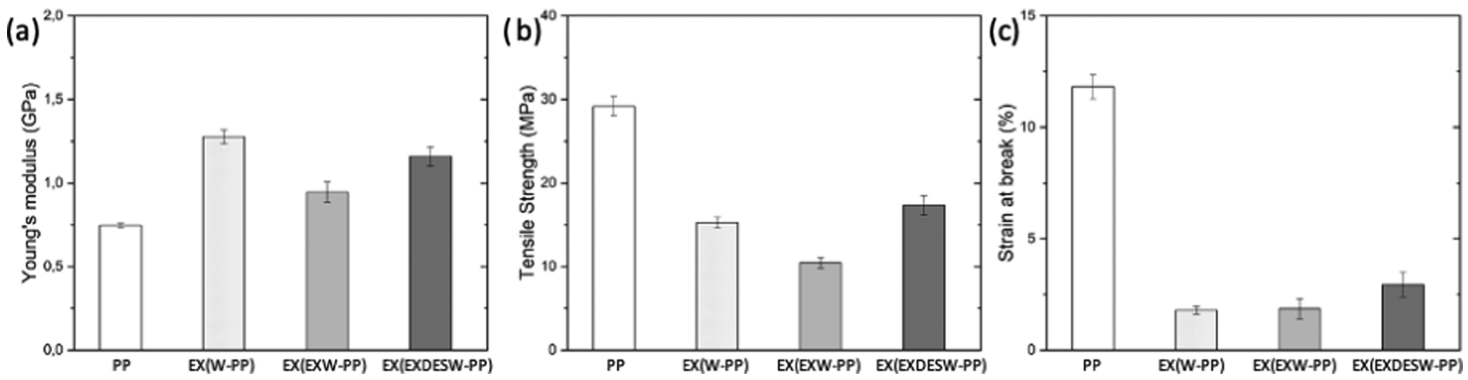

Figure 9. Comparison of the mechanical properties of neat PP and wood-PP composites. (a) Elastic modulus, (b) tensile strength, and (c) strain at break.

and $102 \pm 1^{\circ}$, respectively. The increase in the contact angle of the DES-treated wood composite, close to that of the neat PP, confirmed that the DES treatment affects the wood fibrils surface energy, and this is a very interesting result as this will likely increase the composite moisture stability. Moreover, this result was likely the reason for the better dispersion and distribution of fibrillated wood within the polymer matrix. The overview of composites' microstructures after extrusion is shown in Figure 7. In Figure $7 b$, the composite where the wood sawdust is directly extruded with PP (EX(W-PP)) shows large wood particles comprising wood cells in the PP matrix, while the composites in Figure $7 c$,d, with the fibrillation step EX(EXW-PP) and EX(EXDESW-PP), show that the wood sawdust is separated to individual fibers and even to smaller fractions, which are well distributed and dispersed in the PP.

Mechanical Properties. The composites' mechanical properties and FE-SEM images of the fractured specimen after mechanical testing are shown in Figure 8. Typical stressstrain curves of the prepared wood composites are shown in Figure 8a. Comparing the different composite materials, the composite with DES-treated wood sawdust (EX(EXDESW$\mathrm{PP})$ ) shows the highest maximum strength and elongation, and these properties are lower for nontreated composites (EX(W$\mathrm{PP})$ ) and for (EX(EXW-PP)). The reason for the better strength and elongation can be because of the fibrillation and on a more homogeneous dispersion and distribution of the wood fibers/fibrils within the PP matrix, which is confirmed in the micrographs (presented in Figure 7d). The FE-SEM crosssectional images of the fractured surfaces after mechanical testing (Figure 8) confirm fibrillation of wood, especially the fibrillation of the DES-treated wood materials, the cell wall is separated to thin wood fibrils (Figure $8 \mathrm{~d}$ ). However, these high-resolution images also confirm poor interactions between the wood fiber surfaces and PP as the fiber surfaces are clean, and these are also clearly visible in all images and a gap between the larger wood particles or smaller wood fibrils and the PP polymer are seen in all micrographs.

In Figure 9, the composites' mechanical properties Young's modulus, maximum strength, and elongation at break are compared. It is seen that the maximum strength and elongation at break of the composites are not at the level of the neat PP, and the lower strength especially indicates poor adhesion between the PP and W (as discussed previously and shown in the Figure 8). Furthermore, the Young's modulus was slightly higher for all composites compared with the PP matrix, and the highest for composites without the fibrillation. Elastic modulus values were $1.45 \mathrm{GPa}$ for $\mathrm{EX}(\mathrm{W}-\mathrm{PP}), 1.42 \mathrm{GPa}$ for EX(EXDESW-PP), $0.95 \mathrm{GPa}$ for EX(EXW-PP), and 0.78 $\mathrm{GPa}$ for neat $\mathrm{PP}$, respectively. These results indicate that improved fibrillation did not result in the highest stiffness values as one would expect, the DES pretreatment has not only softened the wood to allow better fibrillation, but also reduced its stiffness. These results are in agreement with the melt rheology data shown in Figure 6c.

In summary, the mechanical tests confirmed that all composites had a higher elastic modulus compared to the matrix polymer (PP). Due to the increased surface energy for fibers and better dispersive mixing, the DES treatment improved the tensile strength and strain at break in the composites compared to the nontreated ones. However, the tensile strength of the composite containing DES-treated W was lower than that of neat PP, which might be related to the TSE compounding step and the poor adhesion of fibers and neat PP. However, we believe this could be improved by using a coupling agent, such as maleic anhydride grafted PP (MAPP). ${ }^{25}$

\section{CONCLUSIONS}

In this study, fibrillation of high consistency wet wood sawdust and environmentally friendly and low-cost DES treatment using the twin-screw extrusion process was investigated. Furthermore, wood-PP (50/50) composites of fibrillated wood sawdust with and without treatment were prepared and studied.

According to the morphological and rheological results, the wood sawdust was fibrillated using only a one-step TSE, and the DES treatment improved the degree of fibrillation and resulted in less fiber breakage. Moreover, the DES treatment of the wood sawdust resulted in a dark brown color and more reduced affinity to moisture and turned the composites to a similar level of hydrophobicity as the PP matrix. Based on fractional test data, the width of more than $70 \mathrm{wt} \%$ of the treated wood material was reduced from $5 \mathrm{~mm}$ to $8 \mu \mathrm{m}$ with an aspect ratio of more than 50 .

The rheological properties of the DES-treated and untreated wood sawdust showed a clearly fibrillated structure. The melt rheology data indicated that the neat PP follows the CoxMerz rule, but for all composites, overlapping of the data occurred at very low shear rates and frequencies. The elastic modulus of all composites was improved in comparison with neat PP, which might be related to the proper compounding and distributive mixing of the fibers and the PP matrix. The tensile strength and strain at break of the DES-treated composite did not improve as expected due to softening of the wood particles using the DES treatment, which diminished the properties in comparison to neat $\mathrm{PP}$, even with improved fibrillation. 
The pretreatment of wood with a green solvent system together with only one extrusion step is a new approach for the fibrillation process that could enable the use of wood raw materials with high consistency and low energy consumption and allow the composite to be extruded in a single step, simplifying the process and reducing the overall cost.

\section{ASSOCIATED CONTENT}

\section{SI Supporting Information}

The Supporting Information is available free of charge at https://pubs.acs.org/doi/10.1021/acssuschemeng.0c07750.

One step twin-screw extrusion process to fibrillate deep eutectic solvent-treated wood to be used in wood fiberpolypropylene composites (MOV)

\section{AUTHOR INFORMATION}

\section{Corresponding Author}

Kristiina Oksman - Fiber and Particle Engineering Research Unit, Faculty of Technology, University of Oulu, FIN-90014 Oulu, Finland; Division of Materials Science, Department of Engineering Sciences and Mathematics, Luleå University of Technology, SE-97187 Luleå, Sweden; Mechanical \& Industrial Engineering (MIE), University of Toronto, Toronto, Ontario M5S 3G8, Canada; (1) orcid.org/00000003-4762-2854; Email: kristiina.oksman@ltu.se

\section{Authors}

Hesam Taheri - Fiber and Particle Engineering Research Unit, Faculty of Technology, University of Oulu, FIN-90014 Oulu, Finland

Maiju Hietala - Fiber and Particle Engineering Research Unit, Faculty of Technology, University of Oulu, FIN-90014 Oulu, Finland

Terhi Suopajärvi - Fiber and Particle Engineering Research Unit, Faculty of Technology, University of Oulu, FIN-90014 Oulu, Finland

Henrikki Liimatainen - Fiber and Particle Engineering Research Unit, Faculty of Technology, University of Oulu, FIN-90014 Oulu, Finland; 이잉.org/0000-0002-79112632

Complete contact information is available at:

https://pubs.acs.org/10.1021/acssuschemeng.0c07750

\section{Notes}

The authors declare no competing financial interest.

\section{ACKNOWLEDGMENTS}

We thank Business Finland (formerly The Finnish Funding Agency for Technology and Innovation, TEKES) for its financial support (grant no. 1841/31/2014) and Bio4Energy Swedish Strategic Research Program for financial support. Dr. Juho Sirviö for FTIR consulting. Ms. Luisa Völtz for mechanical testing with an extensometer, and Mr. Rafal Sliz for contact angle testing are acknowledged. Thanks also to Dr. Petteri Piltonen for his interesting discussions and help with this work.

\section{ABBREVIATIONS USED}

W, wood sawdust; EX, extruded; DES, deep eutectic solvent; TSE, twin-screw extrusion; DESW, deep eutectic solventtreated wood sawdust; PP, polypropylene; EXW, extruded wood sawdust; EXDESW, extruded deep eutectic solvent- treated wood sawdust; SC, short conveying; RC, regular conveying; $2 \mathrm{KE}$, double flights kneading; $3 \mathrm{KE}$, triple flights kneading; MIX, tooth mixing; FE-SEM, field emission scanning electron microscopy; OM, optical microscopy; FTIR, Fourier transform infrared spectroscopy

\section{REFERENCES}

(1) Partanen, A.; Carus, M. Wood and natural fiber composites current trend in consumer goods and automotive parts. Reinf. Plast. 2016, 60, 170-173.

(2) Siró, I.; Plackett, D. Microfibrillated cellulose and new nanocomposite materials: a review. Cellulose 2010, 17, 459-494.

(3) Cicala, G.; Tosto, C.; Latteri, A.; La Rosa, A. D.; Blanco, I.; Elsabbagh, A.; Russo, P.; Ziegmann, G. Green Composites Based on Blends of Polypropylene with Liquid Wood Reinforced with Hemp Fibers: Thermomechanical Properties and the Effect of Recycling Cycles. Materials 2017, 10, No. 998.

(4) Sinquefield, S.; Ciesielski, P. N.; Li, K.; Gardner, D. J.; Ozcan, S. Nanocellulose Dewatering and Drying: Current State and Future Perspectives. ACS Sustainable Chem. Eng. 2020, 8, 9601-9615.

(5) Pickering, K. L.; Efendy, M. G. A.; Le, T. M. A review of recent developments in natural fibre composites and their mechanical performance. Composites, Part A 2016, 83, 98-112.

(6) Oksman, K.; Aitomäki, Y.; Mathew, A. P.; Siqueira, G.; Zhou, Q.; Butylina, S.; Tanpichai, S.; Zhou, X.; Hooshmand, S. Review of the recent developments in cellulose nanocomposite processing. Composites, Part A 2016, 83, 2-18.

(7) Osong, S. H.; Norgren, S.; Engstrand, P. Processing of woodbased microfibrillated cellulose and nanofibrillated cellulose, and applications relating to papermaking: a review. Cellulose 2016, 23, 93-123.

(8) Hietala, M.; Samuelsson, E.; Niinimäki, J.; Oksman, K. The effect of pre-softened wood chips on wood fibre aspect ratio and mechanical properties of wood-polymer composites. Composites, Part A 2011, 42, 2110-2116.

(9) Hietala, M.; Rollo, P.; Kekäläinen, K.; Oksman, K. Extrusion processing of green biocomposites: compounding, fibrillation efficiency and fiber dispersion J. Appl. Polym. Sci. 2014, 131, 39981 6 DOI: 10.1002/app.39981.

(10) Herrick, F. W.; Casebier, R. L.; Hamilton, J. K.; Sandberg, K. R. Microfibrillat cellulose: morphology and accessibility. J. Appl. Polym. Sci.: Appl. Polym. Symp. 1983, 37, 797-813.

(11) Johnson, R. K.; Zink-Sharp, A.; Renneckar, S. H.; Glasser, G. W. A new bio-based nanocomposite: Fibrillated TEMPO-oxidized celluloses in hydroxypropyl-cellulose matrix. Cellulose 2009, 16, 227238 .

(12) Besbes, I.; Alila, S.; Boufi, S. Nanofibrillated cellulose from TEMPO-oxidized eucalyptus fibres: Effect of the carboxyl content. Carbohydr. Polym. 2011, 84, 975-983.

(13) Iwamoto, S.; Nakagaito, A. N.; Yano, H. Nano-fibrillation of pulp fibers for the processing of transparent nanocomposites. Appl. Phys. A 2007, 89, 461-466.

(14) Nechyporchuk, O.; Pignon, F.; Belgacem, M. N. Morphological properties of nanofibrillated cellulose produced using wet grinding as an ultimate fibrillation process. J. Mater. Sci. 2015, 50, 531-541.

(15) Ho, T. T. T.; Zimmermann, T.; Hauert, R.; Caseri, W. Preparation and characterization of cationic nanofibrillated cellulose from etherification and high shear disintegration processes. Cellulose 2011, 18, 1391-1406.

(16) Taheri, H.; Samyn, P. Effect of homogenization (microfluidization) process parameters in mechanical production of microand nanofibrillated cellulose on its rheological and morphological properties. Cellulose 2016, 23, 1221-1238.

(17) Rol, F..; Banvillet, G.; Meyer, V.; Petit-Conil, M.; Bras, J. Combination of twin-screw extruder and homogenizer to produce high-quality nanofibrillated cellulose with low energy consumption. J. Mater. Sci. 2018, 53, 12604-12615. 
(18) Spence, K. L.; Venditti, R. A.; Rojas, O. J.; Habibi, Y.; Pawlak, J. $\mathrm{J}$. A comparative study of energy consumption and physical properties of microfibrillated cellulose produced by different processing methods. Cellulose 2011, 18, 1097-1111.

(19) Josset, S.; Orsolini, P.; Siqueira, G.; Tejado, A.; Tingaut, P.; Zimmermann, T. Energy consumption of the nanofibrillation of bleached pulp, wheat straw and recycled newspaper through a grinding process. Nord. Pulp Pap. Res. J. 2014, 29, 167-175.

(20) Hietala, M.; Niinimäki, J.; Oksman, K. The use of twin-screw extrusion in processing of wood The effect of processing parameter and pretreatment. BioResources 2011, 6, 4615-4625.

(21) Ho, T. T. T.; Abe, K.; Zimmermann, T.; Yano, H. Nanofibrillation of pulp fibers by twin-screw extrusion. Cellulose 2015, 22, 421-433.

(22) Rol, F.; Karakashov, B.; Nechyporchuk, O.; Terrien, M.; et al. Pilot-Scale Twin Screw Extrusion and Chemical Pretreatment as an Energy-Efficient Method for the Production of Nanofibrillated Cellulose at High Solid Content. ACS Sustainable Chem. Eng. 2017, 5, 6524-6653.

(23) Le Baillif, M.; Oksman, K. The effect of processing on fiber dispersion, fiber length, and thermal degradation of bleached sulfite cellulose fiber polypropylene composites. J. Thermoplast. Compos. Mater. 2009, 22, 115-133.

(24) Bengtsson, M.; Le Baillif, M.; Oksman, K. Extrusion and mechanical properties of highly filled cellulose fibre-polypropylene composites. Composites, Part A 2007, 38, 1922-1931.

(25) Hietala, M.; Oksman, K. Pelletized cellulose fibres used in twinscrew extrusion for biocomposite manufacturing: Fibre breakage and dispersion. Composites, Part A 2018, 109, 538-545.

(26) Taheri, H.; Hietala, M.; Oksman, k. One-step twin-screw extrusion process of cellulose fibers and hydroxyethyl cellulose to produce fibrillated cellulose biocomposite. Cellulose 2020, 27, 81058119.

(27) Kim, K. J.; Lee, J. M.; Ahn, E. B.; Eom, T. J. Effect of enzyme beating on grinding method for microfibrillated cellulose preparation as a paper strength enhancer. Cellulose 2017, 24, 3503-3511.

(28) Zhou, H.; St. John, F.; Zhu, J. Y. Xylanase pretreatment of wood fibers for producing cellulose nanofibrils: a comparison of different enzyme preparations. Cellulose 2019, 26, 543-555.

(29) Francisco, M.; van den Bruinhorst, A.; Kroon, M. C. New natural and renewable low transition temperature mixtures (LTTMs): screening as solvents for lignocellulosic biomass processing. Green Chem. 2012, 14, 2153-2157.

(30) Naser, J.; Mjalli, F.; Jibril, B.; Al-Hatmi, S.; Gano, Z. Potassium Carbonate as a Salt for Deep Eutectic Solvents. Int. J. Chem. Eng. Appl. 2013, 4, 114-118.

(31) Sirviö, J. A.; Visanko, M.; Liimatainen, H. Deep eutectic solvent system based on choline chloride-urea as a pre-treatment for nanofibrillation of wood cellulose. Green Chem. 2015, 17, 3401-3406.

(32) Ghaedi, H.; Ayoub, M.; Sufian, S.; Shariff, A. M.; Lal, B.; Wilfred, C. D. Density and refractive index measurements of transition-temperature mixture (deep eutectic analogues) based on potassium carbonate with dual hydrogen bond donors for $\mathrm{CO} 2$ capture. J. Chem. Thermodyn. 2018, 118, 147-158.

(33) Tomé, L. I. N.; Baião, V.; da Silva, W.; Brett, C. M. A. Deep eutectic solvents for the production and application of new materials. Appl. Mater. Today 2018, 10, 30-50.

(34) Suopajärvi, T.; Ricci, P.; Karvonen, V.; Ottolina, G.; Liimatainen, $H$. Acidic and alkaline deep eutectic solvents in delignification and nanofibrillation of corn stalk, wheat straw, and rapeseed stem residues. Ind. Crops Prod. 2020, 145, No. 111956.

(35) Rauwendaal, C. Polymer Extrusion, 5th; Hanser Publishers: Munich, 2013; ISBN 9781569905166.

(36) Laitinen, O.; Niinimäki, J. Fractional study of the microfibrillated cellulose. Tappi J. 2014, 13, 49-55.

(37) He, Y.; Pang, Y.; Liu, Y.; Li, X.; Wang, K. Physicochemical characterization of rice straw pretreated with sodium hydroxide in the solid state for enhancing biogas production. Energy Fuels 2008, 22, $2775-2781$.
(38) Chen, X.; Yu, J.; Zhang, Z.; Lu, C. Study on structure and thermal stability properties of cellulose fibers from rice straw. Carbohydr. Polym. 2011, 85, 245-250.

(39) Lim, W. L.; Gunny, A. A. N.; Kasim, F. H.; AlNashef, I. M.; Arbain, D. Alkaline deep eutectic solvent: a novel green solvent for lignocellulose pulping. Cellulose 2019, 26, 4085-4098.

(40) Bröckel, U.; Meier, W.; Wagner, G. Product Design and Engineering: Formulation of Gels and Pastes; Wiley-VCH Verlag GmbH \& Co.: KGaA, 2013; ISBN 978-3-527-33220-5.

(41) Cox, W. P.; Merz, E. H. Correlation of dynamic and steady flow viscosities. J. Polym. Sci. 1958, 28, 619-622.

(42) Doraiswamy, D.; Mujumdar, A. N.; Tsao, I.; Beris, A. N.; Danforth, S. C.; Metzner, A. B. The Cox-Merz rule extended: a rheological model for concentrated suspensions and other materials with a yield stress. J. Rheol. 1991, 35, 647-686.

(43) Gleissle, W.; Hochstein, B. Validity of the Cox Merz rule for concentrated suspensions. J. Rheol. 2003, 47, 897-910. 